\title{
FORMAÇÃO DE PROFESSORES EM MODELAGEM E A ESCOLA: QUE CAMINHOS PERSEGUIR?
}

\author{
FORMATION OF TEACHERS IN MODELING AND SCHOOL: WHICH \\ WAYS TO GO?
}

\author{
Ana Paula dos Santos Malheiros ${ }^{1}$ \\ Régis Forner ${ }^{2}$ \\ Lahis Braga Souza ${ }^{3}$
}

\begin{abstract}
Resumo: Buscamos, com este texto, discutir possibilidades para a formação de professores em Modelagem, considerando o contexto no qual eles atuam ou irão atuar: as escolas. Em um ensaio teórico, pautado no paradigma qualitativo, e com base em pressupostos freireanos, nosso debate se dá pelo viés das potencialidades da formação de professores frente ao contexto atual em que estamos inseridos, no qual impera um currículo prescrito. Imbricados nesse cenário e a partir de nossas vivências como formadores, defendemos que a escola se constitui como um lócus privilegiado para a formação dos professores e que as pesquisas desenvolvidas podem colaborar com a prática daqueles que estão diretamente envolvidos com os alunos, assim como com os futuros professores. Nessa dinamicidade, advogamos em favor da Modelagem enquanto uma possível abordagem passível de contribuir para a formação e para a prática do professor de Matemática, além de outros significados matemáticos para os alunos em uma perspectiva emancipadora e transformadora.
\end{abstract}

Palavras-chave: Educação Matemática; Formação Inicial de Professores; Formação Permanente de Professores; Paulo Freire.

\begin{abstract}
With this text, we seek to discuss possibilities for teacher training in Modeling, considering the context in which they work or will work: schools. From a theoretical essay, in a qualitative paradigm and based on Freire's assumptions, our debate is based on the potential of teacher education in the current context in which we are inserted, in which a prescribed curriculum prevails. Imbricated in this scenario and from our experiences as formators, we defend that the school constitutes as a privileged locus for the formation of the teachers and that the research developed can collaborate with the practice of those directly involved with students, as well as with future teachers. In this dynamism, we advocate in favor of Modeling as a possible approach that can bring ways for the formation and practice of the Mathematics teacher, in addition to other mathematical meanings for students in an emancipatory and transformative perspective.
\end{abstract}

Keywords: Mathematical Education; Initial Formation of Teachers; Permanent Formation of Teachers; Paulo Freire.

\footnotetext{
${ }^{1}$ Doutora em Educação Matemática pela Universidade Estadual Paulista "Julio de Mesquita Filho" (UNESP). Professora Assistente Doutora e Pesquisadora da Universidade Estadual Paulista "Julio de Mesquita Filho" (UNESP), São José do Rio Preto, SP, Brasil. E-mail: paula.malheiros@unesp.br

2 Doutor em Educação Matemática pela Universidade Estadual Paulista "Júlio de Mesquita Filho" (UNESP). Professor de Matemática e Coordenador Pedagógico junto a Secretaria de Estado da Educação de São Paulo, SP, Brasil. E-mail: regisforner@uol.com.br

${ }^{3}$ Mestre em Educação Matemática na Universidade Estadual Paulista Julio de Mesquita Filho (UNESP).

Doutoranda pela mesma instituição. E-mail: bragalahis@gmail.com
} 


\section{Para início de conversa}

Para fomentarmos as discussões em torno das temáticas que abordaremos neste artigo, faz-se necessário problematizarmos algumas delas, a partir do que temos vivenciado no contexto de nossas práticas e das pesquisas que desenvolvemos nas escolas públicas estaduais paulistas, assim como aquelas da formação de professores de Matemática. Cabe ressaltar que, embora enfatizemos nosso contexto, as escolas públicas do Estado de São Paulo, a política pautada na economia de mercado nelas desenvolvidas é realidade em outros cenários no Brasil (CARA, 2019a). Não se pode negligenciar, também, que algumas dessas discussões são oriundas da nossa imersão na literatura que trata da Modelagem em Educação Matemática e da Formação de Professores, sob o viés da Modelagem 4 .

Ao debruçarmos em pesquisas que discutem sobre a gênese da Modelagem no contexto brasileiro, como as realizadas por Biembengut (2009) e por Fillos (2019), percebemos que ela se difundiu, no Brasil, por meio de cursos para professores realizados a partir da década de 1980, evidenciando um caráter prático. Entendemos, a partir da leitura de diferentes textos que tratam sobre a chegada da Modelagem em nosso país, que uma das principais preocupações era a formação de professores para que mudanças ocorressem nas aulas de Matemática, por meio da Modelagem.

Essa preocupação, mesmo que algumas décadas depois, mais precisamente em 2006, se manifesta em documentos oficiais que orientam a Educação Básica em nível nacional, como na Orientações Curriculares para o Ensino Médio (BRASIL, 2006), tendo como objetivo apresentar potencialidades da Modelagem para o ensino de Matemática nas escolas públicas brasileiras. Neste documento, a Modelagem é compreendida como uma estratégia de ensino, além de uma habilidade de transformar situações da realidade em problemas matemáticos, para resolução e interpretação no mundo real (BRASIL, 2006).

$\mathrm{Na}$ mesma direção, ocorreram movimentos semelhantes em outras diretrizes curriculares, como as do estado do Paraná (PARANÁ, 2008), em que a Modelagem é sugerida como um ambiente de aprendizagem, no qual os estudantes exercem um papel proativo e o professor, orientador e mediador, distinto de outras práticas que tem o professor como o único protagonista. Mais recentemente, de forma superficial, na Base

\footnotetext{
${ }^{4}$ Neste texto, utilizaremos Modelagem, Modelagem em Educação Matemática e Modelagem Matemática como sinônimos, com intuito de evitar repetições.
} 
DOI: http://dx.doi.org/10.33238/ReBECEM.2020.v.4.n.1.24566

Nacional Comum Curricular (BNCC), a Modelagem é apresentada como um dos processos matemáticos privilegiados de atividades e de estratégia para a aprendizagem da Matemática (BRASIL, 2018). Ainda, no atual Currículo Paulista: Matemática e suas Tecnologias, ela é apresentada como uma possibilidade de trabalho pedagógico dos professores, levando em consideração as necessidades de os alunos entenderem situações de seu cotidiano por meio de problemas e investigação (SÃO PAULO, 2019).

A partir desse breve olhar acerca da presença da Modelagem Matemática nas orientações curriculares, é possível inferir que ela está relacionada à ideia do trabalho com a Matemática a partir de temas considerados não matemáticos, de modo a torná-la mais próxima do contexto dos estudantes. Entendemos a Modelagem como um caminho para o "fazer" Matemática em sala de aula, pois a partir de observações do cotidiano e de questionamentos, discussões, diálogos, problematizações e investigações, os estudantes se deparam com situações-problema que podem modificar as ações na sala de aula, além da forma como se compreende o mundo. Tal ideia se aproxima daquilo que Freire (2005) denomina "leitura de mundo". Para nós, esse é o principal entendimento sobre Modelagem, desde os cursos para os professores, décadas atrás.

De forma paralela, as pesquisas em Modelagem Matemática tiveram um crescimento profícuo, muitas delas realizadas a partir de práticas desenvolvidas que, implicitamente ou explicitamente, tinham por objetivo difundir essa abordagem com potencialidades para a escola. Segundo Barbosa (2001), tais investigações têm ocorrido desde os anos 1990, mesmo assim não possibilitaram que a Modelagem chegasse efetivamente nas aulas de Matemática.

Esse esforço instigou pesquisas que buscaram por investigar possíveis obstáculos que impediam que a Modelagem lograsse êxito no ensino e na aprendizagem da Matemática no contexto escolar. Estudos como Silveira e Caldeira (2012) evidenciam algumas dificuldades e resistências que emanam dos mais diferentes vieses do complexo contexto educacional brasileiro. Essas se dão nas relações do professor com o trabalho, na "preparação das aulas; relação com os alunos relação com a família dos alunos; estrutura administrativa pedagógica das escolas; currículos e questões pessoais, como por exemplo, a insegurança diante do novo" (SILVEIRA; CADEIRA, 2012, p. 1043).

Essas considerações se confirmam por outras pesquisas, como de Magnus (2012), realizada com professores da rede pública estadual do estado de Santa Catarina. Dos participantes, parte trabalhava ou continuava trabalhando com a Modelagem em sala de 


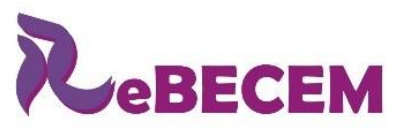

Revista Brasileira de Educação em

Ciências e Educação Matemática

DOI: http://dx.doi.org/10.33238/ReBECEM.2020.v.4.n.1.24566

aula, mas destacavam não ser simples utilizá-la, apontando obstáculos que os impedem ou desmotivam.

Entre os obstáculos evidenciados pela investigação de Magnus (2012) estão a falta de conhecimento ou formação do professor e a insegurança em trabalhar com Modelagem. Outros empecilhos apontados na pesquisa são: a falta de tempo, tanto para o planejamento das aulas, em razão da alta carga horária dispendida para tal, quanto para o desenvolvimento das atividades de Modelagem em sala de aula e; o rol de conteúdos que deve ser cumprido pelo currículo, muitas vezes imposto, além daquelas aulas que estão relacionadas ao preparo dos estudantes para vestibular e concursos. A pesquisa aponta ainda a inexistência de materiais disponíveis, a falta de apoio dos gestores das escolas e resistência dos alunos em aulas diferenciadas (MAGNUS, 2012).

Magnus (2012) assinala também que devido à falta de tempo do docente, por exemplo, práticas consideradas conservadoras acabam por direcionar o professor a algo que seja mais cômodo e que esteja em sua zona de conforto (PENTEADO, 1999). A autora (MAGNUS, 2012) evidencia, a partir dos resultados de sua pesquisa, a necessidade de uma formação inicial em Modelagem Matemática e também a realização de cursos de formação continuada, por meio de uma política educacional e na mobilização de pesquisadores em ofertarem mais cursos.

Outra pesquisa, também com foco nos obstáculos para se implementar a Modelagem nas escolas, trouxe resultados que se mostraram mais relacionados à formação inicial de professores de Matemática. Ceolim e Caldeira (2017), ao questionarem professores paranaenses recém-formados, evidenciaram as fragilidades quanto ao uso e desenvolvimento da Modelagem em sala de aula na Educação Básica, a saber, aquelas relacionadas aos fatores de ordem pessoal-emocional, competência profissional e institucional.

Quanto ao fator pessoal-emocional, Ceolim e Caldeira (2017) apontam ter relação com necessidades de mudanças na prática pedagógica, o que os colocam em um ambiente de incertezas e insegurança. Sobre a competência profissional, os autores associam a falta de preparo para fazer uso da Modelagem ao fato de os professores não terem tido uma base prática e teórica sólida sobre ela. Por fim, o institucional, está relacionado a necessidade de quebrar barreiras na estrutura das escolas, que possui um currículo linear e prescrito. Ceolim e Caldeira (2017) inferem ainda que a utilização da Modelagem em sala de aula tem suas fragilidades relacionadas aos três fatores e "que são todos fatores 
DOI: http://dx.doi.org/10.33238/ReBECEM.2020.v.4.n.1.24566

imbricados diretamente com a exigência de mudanças de práticas pedagógicas" (CEOLIM; CALDEIRA, 2017, p. 773).

Os autores Ceolim e Caldeira (2017) identificaram, ainda, um clima de insegurança dos professores em utilizar Modelagem em suas aulas, evidenciando algumas defasagens na formação inicial, bem como dificuldades em se envolver os estudantes em um ambiente de Modelagem. Os resultados também apontaram que a postura tradicional e conservadora que se propaga pelos professores, gestores e até da família pode ser um agravante para que a Modelagem não chegue às escolas.

Sobre os trabalhos que discutem os obstáculos para a inserção da Modelagem nas aulas de Matemática (MAGNUS, 2012; SILVEIRA; CALDEIRA, 2012), Foss e Klüber (2019) fizeram uma análise e concluíram que "o discurso que sustenta a pesquisa sobre obstáculos está assentado no sentido de que os professores são fonte de resistência à Modelagem Matemática, uma vez que estes não se mostram inovadores em suas práticas” (FOSS; KLÜBER, 2019, p. 9, grifos dos autores), embora outros obstáculos sejam mencionados nos estudos investigados. Para os autores, não devemos colocar apenas nos ombros dos professores a responsabilidade pela pouca presença da Modelagem Matemática nas escolas. Para Foss e Klüber (2019), enquanto comunidade acadêmica que investiga questões acerca da Modelagem em Educação Matematica, podemos pensar em ações efetivas para contribuir com a superação da situação. Concordamos com os autores e entendemos que nesse processo, talvez os professores sejam os menos responsáveis pela tímida presença da Modelagem nas escolas.

A partir do que apresentamos, podemos sintetizar que o surgimento da Modelagem, no contexto da Educação Matemática, foi com uma das principais preocupações a formação de professores, para que mudanças ocorressem nas aulas de Matemática. Ainda, temos os documentos oficiais que trazem a Modelagem Matemática como uma possibilidade para o ensino e a aprendizagem de Matemática, desde o início do século. Em contrapartida, temos várias pesquisas que mostram que a Modelagem não está na escola, por vários motivos, como a falta de formação dos professores e também devido às suas condições de trabalho.

Diante do cenário apresentado até então, e a partir de nossas pesquisas (FORNER, 2018; MALHEIROS, 2016; MALHEIROS; HONORATO, 2017; FORNER; MALHEIROS, 2019a, 2019b), entendemos ser fundamental olharmos para as escolas de Educação Básica, ponderando suas realidades, e discutirmos as possibilidades da Modelagem a partir desse contexto, evidenciando as possibilidades para a formação dos 


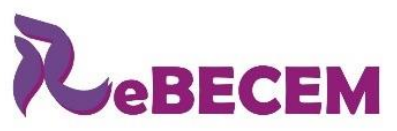

Revista Brasileira de Educação em

Ciências e Educação Matemática

DOI: http://dx.doi.org/10.33238/ReBECEM.2020.v.4.n.1.24566

professores, que entendemos ser permanente (FREIRE, 2000). Assim, nos propomos discutir possibilidades para a formação de professores em Modelagem, considerando em particular a realidade atual das escolas públicas. Para isso, partimos do cenário atual das escolas brasileiras, em particular das públicas do estado de São Paulo. Apresentamos, na sequência, questões relacionadas à formação de professores em Modelagem, para então apresentarmos nossas considerações, a partir de nossas vivencias e pesquisas no contexto da formação de professores em Modelagem.

No que diz respeito à metodologia, esse texto foi elaborado a partir de reflexões, oriundas das pesquisas que realizamos, que de certa maneira representam o que pensamos em termos da formação de professores de Matemática em Modelagem. Desse modo, entendemos que ele está pautado no paradigma qualitativo e pode ser concebido como um ensaio teórico, considerado como uma exposição lógica, coerente e crítica de argumentação sobre um determinado tema (DEMO, 1995). Ainda, em um ensaio teórico o caminho metodológico é tácito.

\section{De que escola falamos?}

Não podemos deixar fora do debate, ao pensar em possibilidades de superação dos obstáculos apresentados (SILVEIRA; CALDEIRA, 2012; MAGNUS, 2012; CEOLIM; CALDEIRA, 2017), de que escola estamos falando, considerando que é dela que também partem nossas reflexões. Apesar das escolas terem muitas similaridades, apresentamos alguns aspectos percebidos por nós, frutos de nossas pesquisas (FORNER, 2018; MALHEIROS, 2016; FORNER; MALHEIROS, 2017, 2018a, 2018b, 2019a, 2019b), para a contribuição dos debates em torno do papel da escola na formação de professores em Modelagem. Consideramos importante destacar que autores como Klüber e seus colaboradores (CARARO; KLÜBER, 2020; MUTTI; KLÜBER, 2018; KLÜBER, 2017) também têm discutido sobre a formação de professores em Modelagem nas escolas, com um olhar para o estado do Paraná. Nos inspiramos em seus estudos e acreditamos que eles têm contribuído muito para as discussões da área.

Destacamos que nossas discussões e reflexões encontram eco na afirmação a seguir, presente no trabalho de Fernandes (2014, p. 101): “[...] se conversarmos com professores que formam professores, percebemos que a grande parte deles não sabe o que acontece na escola básica”. Identificamos que essa é uma realidade, em particular no contexto da Educação Matemática, nossa área de atuação. Por isso, entendemos ser 


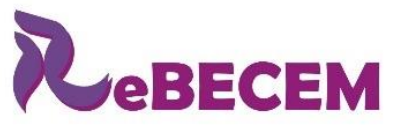

Revista Brasileira de Educação em

Ciências e Educação Matemática

DOI: http://dx.doi.org/10.33238/ReBECEM.2020.v.4.n.1.24566

importante enfatizar o atual cenário educacional e, a partir dele, pensar em possibilidades para que a Modelagem possa adentrar às salas de aula da Educação Básica.

Para tanto, primeiramente, há de se tecer algumas considerações sobre a gênese da BNCC (BRASIL, 2018), visto ser este um documento que historicamente deveria trazer diretrizes para a Educação Básica, apresentar implicitamente algum entendimento sobre o que entende por escola e evidenciar alguns aspectos importantes e necessários para a formação de professores.

Inicialmente, se vislumbrava um panorama democrático, de contribuição dos mais diversos segmentos escolares com a sua elaboração, o que de fato não ocorreu. A BNCC acabou por se concretizar em um documento impositivo, elaborado sem a devida transparência e sem participação da sociedade civil, pois embora aconteceram consultas públicas do documento e seminários estaduais para discussão, sua versão final foi homologada pelo Ministério da Educação sem a devida transparência do órgão (BIGODE, 2019).

Considerando, em particular, a Educação Matemática, de acordo com Bigode (2019), um dos retrocessos da BNCC é indicar que a Matemática seja ensinada nas escolas de modo linear, hierarquizado, rígido e de uma única forma, além de desconsiderar as pesquisas em Educação Matemática realizadas nas últimas décadas e os próprios Parâmetros Curriculares Nacionais. Ademais, a BNCC acabou por controlar e desvalorizar cada vez mais o professor, pois sua função se vincula estritamente em subsidiar avaliações de larga escala e a produção de livros didáticos (CARA, 2019b).

Na mesma direção, Cássio (2019) denuncia problemáticos sistemas de ensino de alguns estados, que fazem uso das avaliações externas censitárias em mecanismos de controle e responsabilização. Eles abarcam diretrizes curriculares, formas de gestão escolar e políticas de bonificações financeiras, com o firme propósito de propagandear ideias capitalistas, que de longe estão em sinergia com o sentido político e cultural que anseamos da escola, baseados em uma perspectiva libertadora da educação (FREIRE, 2005).

Ao tratar sobre cerceamento de professores e de controle do trabalho destes por meio das avaliações de larga escala e seus resultados, dificilmente se desvincula do que Stephan Ball conceituou como cultura da performatividade. Para Ball (2005), o que se vislumbra é um "sistema de terror" no qual se vivencia um espetáculo ou uma fantasia encenada. Em termos práticos, por meio de instrumentos coercitivos, o professor, muitas vezes sem perceber, acaba por apregoar ideias próprias do sistema globalizado e 
DOI: http://dx.doi.org/10.33238/ReBECEM.2020.v.4.n.1.24566

neoliberal, que cada vez mais se difunde no meio educacional. Sobre tais questões, temos em Freire (2005, p. 76, grifos nossos) que

a educação como prática de dominação, que vem sendo objetivo dessa crítica, mantendo a ingenuidade dos educandos, o que pretende, em seu marco ideiológico (nem sempre percebido por muitos que o realizam) é indoutrinálos no sentido de sua acomodação ao mundo de opressão.

Essas considerações, para nós, se tornam mais vistosas e evidentes, frente ao que presenciamos e vivenciamos nas escolas estaduais paulistas. Todos os professores e alunos devem fazer uso de um Material Didático do Estado de São Paulo, proposto em 2008 pela Secretaria de Educação, organizados por disciplina/série(ano)/bimestre, dirigidos aos professores e alunos (SÃO PAULO, 2012). Estes materiais, conhecidos como caderninhos, são organizados em Situações de Aprendizagem, que nada mais são que materializações das diretrizes curriculares paulistas. Sabemos que ao professor cabe a liberdade de cátedra e não há existência de nenhum documento oficial que coloque isso a prova, porém na prática o que temos são instrumentos coercitivos que muito estão imbricados com a cultura da performatividade.

Essa coerção, se não fosse melhor dizer opressão, se dá por muitos vieses. Um deles é a existência de Avaliações de Aprendizagem em Processo (AAP's) que tem como objetivo "preparar" o estudante para a avaliação externa denominada Sistema de Avaliação de Rendimento Escolar do Estado de São Paulo (SARESP). A partir do desempenho nesta avaliação, é gerado um índice, o Índice de Desenvolvimento da Educação do Estado de São Paulo (IDESP), que além de ranquear as escolas também pode, dependendo do alcance da meta previamente imposta à escola, convergir em bonificações financeiras para os professores que obtiverem boas notas de seus alunos, ao invés de uma melhora na valorização e remuneração desses professores. Estudos já mencionaram tal fato com a disciplina e os professores de Matemática (CRECCI; FIORENTINI, 2014; MALHEIROS; HONORATO, 2017; FORNER, 2018), o que muitas vezes dificulta o desenvolvimento de abordagens metodológicas distintas, como a Modelagem, em suas aulas.

O que acaba por se verificar nesses contextos é que, apesar dos documentos oficiais abordarem como uma das possibilidades para as aulas de Matemática a Modelagem, na prática notamos que os professores são obrigados a cumprir o currículo de forma linear, utilizando apenas o que está posto nos materiais didáticos. O professor acaba por ser controlado e muitas vezes, mesmo que sem perceber, se esforça em "treinar" seus alunos, resolvendo determinados exercícios para que possam alcançar notas boas nas 
DOI: http://dx.doi.org/10.33238/ReBECEM.2020.v.4.n.1.24566

avaliações externas, para que assim ele e seus colegas de trabalho possam ser recompensados financeiramente ${ }^{5}$. Alguns, mesmo que não concordando com essa perversidade, acabam por seguir essa nefasta lógica, com receio de serem culpados pelo não alcance das metas. Decorre que toda equipe escolar acaba por ser "penalizada" e por criar uma verdadeira "caça às bruxas", tentando achar o culpado, que não está nas escolas, mas nos órgãos reguladores. Vê-se um cenário problemático onde o ensino e a aprendizagem, que deveriam ser os principais objetivos da escola, não estão em primeiro lugar. Temos uma Educação Bancária (FREIRE, 2005), não emancipatória, sem diálogo, com o principal objetivo de alcançar índices.

Nesse modelo de educação, a Bancária (FREIRE, 2005), imposta muitas vezes pelo sistema, o professor aparece como um ser inquestionável, com a missão de "encher" os estudantes com determinados conteúdos previstos nos currículos e que são ou estão desconectados das realidades dos alunos. Essa postura relega a educação a um simples ato de depositar, guiando os alunos a memorização de conteúdos e procedimentos para sua reprodução (FREIRE, 2005). Nessas aulas predominam o uso dos materiais didáticos como os caderninhos (SÃO PAULO, 2012) e elas são realizadas a partir de explicação dos conteúdos e resolução de exercícios na lousa, ressaltando fórmulas e procedimentos a serem adotados. Ao final da aula, os estudantes devem "mostrar" o que aprenderam, resolvendo listas de exercícios semelhantes ao qual o professor expôs e que, em muitas vezes, pela concepção do professor, apresenta uma única resposta correta.

Essa é a escola que temos, salvo algumas exceções, e, a partir da complexidade de relações que acontecem nela é que nossas pesquisas estão focadas, em especial, nas potencialidades da Modelagem frente a esse contexto. Indissociável a essas questões estão as investigações com foco na formação de professores em Modelagem.

\section{Formação de professores em modelagem}

Quando nos debruçamos sob documentos que tratam da formação de professores em Matemática, encontramos em Brasil (2001) que os currículos dos cursos de licenciatura devem ser elaborados de forma a desenvolver determinados aspectos considerados importantes para a atuação em sala de aula. Alguns deles estão focados na busca pelo estabelecimento de relações entre a Matemática e outras áreas do

\footnotetext{
${ }^{5}$ Entendemos que o sistema acaba por obrigar o professor a entrar na lógica imposta, devido aos baixos salários a que estão expostos.
} 


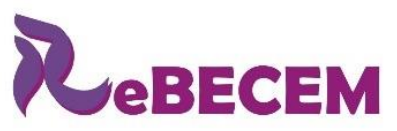

Revista Brasileira de Educação em

Ciências e Educação Matemática

DOI: http://dx.doi.org/10.33238/ReBECEM.2020.v.4.n.1.24566

conhecimento, uma das preocupações de pesquisadores em Modelagem, como identificados nos estudos de Braz $(2014 ; 2017)$, nos quais são discutidas e apresentadas possibilidades da Modelagem no contexto da formação inicial de professores de Matemática.

Pensando em ações formativas que estejam relacionadas ao desenvolvimento de tais aspectos, em Burak e Malheiros (2017), há o relato de tentativas de implementação de atividades por alunos licenciandos em Matemática que estavam realizando Estágio Curricular Supervisionado em uma escola pública paulista. No entanto, tais atividades eram adaptadas, aliando o Material do Estado de São Paulo com a Modelagem Matemática. Tal modo de uso de Modelagem na sala de aula, também é relatado por Honorato (2016) que traz algumas possibilidades para aliar Modelagem e currículo, sendo uma delas utilizar atividades "mais direcionadas, nas quais haveria uma mediação maior do professor, contudo, concomitantemente, os estudantes não deixariam de serem protagonistas e de construir seus próprios conhecimentos" (HONORATO, 2016, p. 129). O autor salienta, também, que outro meio de desenvolvimento de atividades de Modelagem pode ocorrer

tanto na escolha do tema, no início da atividade, quanto no decorrer dela.
Emergiram também alternativas de elaboração de atividades de Modelagem
articuladas com Situações de Aprendizagem, presentes no material didático,
podendo ser a partir de temas de interesse dos estudantes (ou que possam
interessá-los) ou das próprias Situações de Aprendizagem (HONORATO,
2016, p. 126).

Assim, Honorato (2016) entende que o modo apresentado por ele pode propiciar que o docente da turma aborde os conteúdos previstos no currículo por meio de situações que partem do cotidiano do aluno ou que possa ser de interesse dos mesmos.

Diante de algumas possibilidades já apresentadas na literatura e da realidade das escolas, nossa preocupação reside em pensar em ações formativas que partam das prerrogativas legais, mas que considerem a escola como lócus privilegiado de formação. Para isso, entendemos que os professores e futuros professores devem vivenciar a escola da forma como ela é, e que no exercício reflexivo sejam analisadas e implementadas propostas que estejam voltadas a transformação e emancipação dos estudantes, considerando que eles não sejam apenas expectadores, mas sim protagonistas de sua história. Nesse sentido, apresentamos algumas experiências, oriundas das pesquisas que realizamos, que de certa maneira, representam em termos práticos, o que pensamos em termos de formação de professores de Matemática e que podem contribuir com a discussão que objetivamos com este texto. 


\section{Alguns possíveis caminhos}

A partir das considerações trazidas nas seções anteriores, urge a necessidade de refletirmos quanto à formação de professores em Modelagem e que possíveis caminhos podemos perseguir tendo como ponto de partida o contexto atual das escolas que já enunciamos anteriormente.

Sabemos que embora as escolas estejam dentro de um sistema e sigam regras impostas, temos que considerar que elas, diferente do que se pode pensar, não são apenas diferentes em sua aparência, na fachada ou na disposição dos espaços físicos. Existem também distintas e complexas relações que tornam cada escola como única, muitas delas advindas das interações entre os seres humanos, destacando aquelas entre os estudantes, entre os professores e entre professor e estudantes.

Em razão disso, é inconcebível pensar em uma formação que se ancora em um modelo único de escola e que ignora as complexidades que ali residem. Ao invés disso, pregamos um modelo de formação que parte das especificidades das escolas e, para isso, defendemos que haja um vínculo mais estreito entre ela e a universidade.

Ao nosso ver, esse vínculo torna-se profícuo quando, por exemplo, os estudantes, futuros professores, confrontam seus saberes advindos de sua história e de seu processo formativo com as práticas ocorridas na escola. Nesta direção, o trabalho com a Modelagem na formação inicial de professores de Matemática tem sido tema de práticas e pesquisas há quase uma década pela primeira autora desse artigo, que trabalha com as disciplinas de Estágio Curricular Supervisionado, para o curso de Licenciatura em Matemática em uma instituição pública paulista. Em Malheiros (2014) foram apresentados os primeiros resultados de um estudo que envolveu formação inicial de professores de Matemática e Modelagem na Educação Matemática e, desde então, as práticas e pesquisas têm perseguido a seguinte questão: "que Modelagem é possível de ser trabalhadas nas escolas estaduais paulistas?", considerando principalmente as particularidades apresentadas neste texto.

Em Malheiros (2016), Honorato (2016) e Malheiros e Honorato (2017) são apresentadas possibilidades de trabalho com a Modelagem no contexto das escolas públicas estaduais paulistas, considerando tanto a insegurança dos futuros professores como a imposição do uso do material didático do estado de São Paulo.

Para os licenciandos, de um modo geral, ficou a impressão de que é difícil trabalhar com a Modelagem em turmas regulares, devido ao envolvimento do professor com o tema, a questão do diálogo, etc. Para eles, o modelo de escola 
DOI: http://dx.doi.org/10.33238/ReBECEM.2020.v.4.n.1.24566

que temos dificulta a inserção da Modelagem nas aulas de Matemática da Educação Básica, fato já evidenciado por Caldeira (2015). Os outros licenciandos sempre teciam comentários e faziam reflexões na mesma direção. Entretanto, eles chegaram à conclusão de que seria possível, mas que é uma atividade que deve ser iniciada "aos poucos" até que eles adquiram segurança e que os alunos "se acostumem" com essa "nova" possibilidade de trabalho com a Matemática em sala de aula. Ainda, a questão da obrigatoriedade do uso dos materiais didáticos foi amplamente debatida e questionou-se como que eles poderiam ser aliados ao trabalho com Modelagem em sala de aula (MALHEIROS, 2016, p. 1163).

Em Malheiros e Honorato (2017), por exemplo, alguns resultados foram apresentados. Os futuros professores destacaram algumas limitações referentes ao trabalho com a Modelagem relacionado ao material didático do estado de São Paulo. Para eles, o fato de não existir um roteiro pode ser considerado como um dos percalços ao se trabalhar com a Modelagem, mesmo em uma perspectiva mais "fechada" (BARBOSA, 2009), visto que muitos elementos não previstos podem surgir, característica natural do trabalho com a Modelagem. Eles também ressaltaram que possivelmente não seria possível cumprir todos os conteúdos, competências e habilidades propostos nas Situações de Aprendizagem, mas apenas parte deles, o que também entendemos como natural ao se trabalhar com a Modelagem. Por outro lado, pensamos que outras questões, não previstas no material, poderão surgir e complementar o trabalho, algo desejável quando a Modelagem é abordada na sala de aula.

Ainda,

\begin{abstract}
Eles [os licenciandos] evidenciaram que o trabalho na Educação Básica apenas poderia ser realizado com a Modelagem em uma perspectiva mais fechada, próximo ao que Barbosa (2009) denomina de Caso 1. Por outro lado, um dos sujeitos vislumbrou a possibilidade de trabalhar mais próximo do Caso 2, valorizando, entretanto, as soluções que estivessem mais próximas do conteúdo que se desejaria trabalhar. Para nós, tal fato se deve à natureza das atividades de Modelagem, que variam na perspectiva de cada um dos professores, assim como do contexto no qual o trabalho será realizado. Assim, entendemos que as visões apresentadas pelos futuros professores também podem ter relação com as vivências deles durante o estágio supervisionado (MALHEIROS; HONORATO, 2017, p. 12).
\end{abstract}

A ideia com essa pesquisa não era, de modo algum, reforçar a imposição do material didático em sala de aula e sim encontrar alternativas para que a Modelagem pudesse, de algum modo, estar presente nas aulas de Matemática

Diante de tais investigações e resultados, como os apresentados anteriormente, para nós, tornam-se ainda mais interessantes as reflexões que se dão por esse confronto e que essas sejam analisadas e discutidas no ambiente universitário, constituindo o que Freire (2005) concebeu como práxis, que pode ser entendida como "reflexão e ação dos homens sobre o mundo para transformá-lo" (FREIRE, 2005, p. 38), ou seja, o 


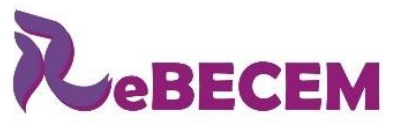

Revista Brasileira de Educação em

Ciências e Educação Matemática

DOI: http://dx.doi.org/10.33238/ReBECEM.2020.v.4.n.1.24566

compromisso entre a palavra dita e nossa ação humanizadora, em um processo de açãoreflexão. Assim, em nossa leitura, o futuro professor ao refletir e agir, considerando as vivências na universidade e na escola, adquire conhecimento para transformar suas concepções sobre o ensino e a aprendizagem.

Nessa direção que temos pesquisado sobre a formação dos professores em Modelagem, ao discutir suas potencialidades, por meio da literatura, e também ao trabalhá-la, na prática, nas atividades de estágio curricular supervisionado. No estágio, temos oportunidade de desenvolver atividades de Modelagem, junto com os licenciandos, e assim buscar formas possíveis de superação de alguns obstáculos ou desempenhos insatisfatórios em determinados conteúdos matemáticos, além da discussão do papel social da Matemática. A transformação pode se dar quando essas experiências são compartilhadas e colocadas em reflexão pelos futuros professores, direcionando a verdadeiras mudanças nas percepções desses estudantes, do ensino e da aprendizagem da Matemática.

Outro possível caminho, partindo da complexidade das escolas, é difundir no ambiente formativo alguns referenciais que evidenciem que a formação inicial não dará conta de todas as adversidades e situações que ocorrem, ou que porventura possam ocorrer em sala de aula, e que a formação não se dá apenas em atividades isoladas e pontuais. Isso significa que a formação adquire um caráter permanente (FREIRE, 2000), na direção de que todos nós, a partir de um referencial freireano, somos seres inacabados, em estado de busca pela completude.

O inacabamento, segundo Freire (2000, p.49), é um "permanente processo de busca e reinvenção do próprio mundo e de si mesmo" e para Trombetta e Trombetta (2017, p. 221) "somos um ser por fazer-se; um ser no mundo e com os outros envolvidos em um processo contínuo de desenvolvimento intelectual, moral, afetivo”. Nesse sentido, inacabamento tem uma íntima relação com formação permanente, por entender que o ser humano se encontra em construção e o professor não é e nunca será uma exceção.

Sendo assim, às universidades cabe despertar o sujeito para que ele se reconheça em estado constante de formação, de que ele enquanto professor precisa buscar estratégias e metodologias que se adequem as demandas que exigem a sociedade contemporânea. Para isso, precisamos disseminar posturas que incentivem a escuta, o diálogo e a colaboração, conceitos tão difundidos por Paulo Freire, que podem impactar em ações efetivas em sala de aula. Nessa direção defendemos a Modelagem como uma possível abordagem pedagógica capaz de trazer esses elementos para as aulas de Matemática, ou 


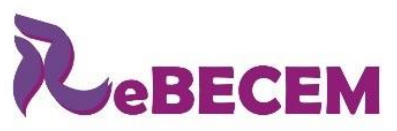

Revista Brasileira de Educação em

Ciências e Educação Matemática

DOI: http://dx.doi.org/10.33238/ReBECEM.2020.v.4.n.1.24566

seja, apresentar para os futuros professores uma abordagem que seja uma alternativa que confronte a visão de que o ensino de Matemática se alicerça em práticas bancárias.

Ainda, entendemos a formação do professor como um processo contínuo e complexo. A complexidade se dá em razão dos estudos de Tardif (2012) e a continuidade a partir de Paulo Freire. Em Tardif (2012, p. 36), o saber docente é apresentado como "um saber plural, formado pelo amálgama, mais ou menos coerente, de saberes oriundos da formação profissional e de saberes disciplinares, curriculares e experienciais", ou seja, podem ser considerados variados na medida em que se dão na confluência de vários deles, como os sociais, os escolares, os da universidade, etc. Tal visão é corroborada por Mizukami (2006, p. 214), que evidencia que

os processos de aprender a ensinar, de aprender a ser professor e de desenvolvimento profissional de professores são lentos, iniciam-se antes do espaço formativo dos cursos de licenciatura e se prolongam por toda vida. A escola e outros espaços de conhecimentos são contextos importantes nessa formação.

Com isso, admitir que o saber docente é constituído de diferentes saberes e que estes são produzidos por e em diversos espaços é reconhecer que nomear a formação como inicial e continuada é adotar uma visão reducionista do processo formativo (FORNER, 2018).

Nesta direção, também, temos desenvolvido trabalhos com os professores da Educação Básica, em uma perspectiva de formação permanente, como relatado em Forner (2018) e Forner e Malheiros (2017; 2019a). Elementos como insegurança e a imposição da utilização dos caderninhos foram evidenciados, mas "superados" a partir da colaboração do grupo de professores participantes da experiência ${ }^{6}$, com ideias que permitiram pensar em uma atividade de Modelagem inspirada em elementos de uma Situação de Aprendizagem (FORNER; MALHEIROS, 2017).

Em sua pesquisa, Forner (2018) buscou evidenciar algumas reflexões que emanam de um contexto em que se busca uma possibilidade de implementação da Modelagem em um ambiente permeado por um currículo prescrito, as escolas públicas estaduais paulistas. Para tanto, foi elaborado um curso que teve por objetivo apresentar essa abordagem pedagógica aos professores que, em sua maioria, desconheciam a Modelagem, e elaborar atividades que poderiam ser desenvolvidas em sala de aula. Tal curso, foi pensado em uma abordagem na qual os professores participassem efetivamente de sua concepção,

\footnotetext{
${ }^{6}$ Um curso para professores de Matemática da Diretoria de Ensino de Limeira, SP. Detalhes em Forner (2018).
} 


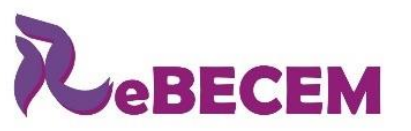

Revista Brasileira de Educação em

Ciências e Educação Matemática

DOI: http://dx.doi.org/10.33238/ReBECEM.2020.v.4.n.1.24566

pautado no diálogo entre iguais e na colaboração, considerando a equidade e o protagonismo de todos, conforme os pressupostos freireanos. Portanto, embora tivéssemos um planejamento inicial, a demanda dos professores foi considerada em todos os encontros e mudanças efetivas aconteceram (FORNER, 2018).

As atividades elaboradas pelos professores ao longo do curso, contexto da pesquisa de Forner (2018), foram feitas de forma colaborativa. Os professores buscavam compartilhar suas experiências, e, por meio do diálogo e problematização, procurando alternativas para poder levar a Modelagem para as aulas de Matemática. Para Forner (2018), a Modelagem pode ocupar espaço nas aulas de Matemática na Educação Básica, desde que haja um movimento em torno da compreensão das situações-limite, que podem ser compreendidas como barreiras que devem ser superadas (FREIRE, 2010), e da proposição de inéditos-viáveis, que podem se dar por meio da constituição de um espaço colaborativo dentro da escola, aquilo considerado como uma barreira pode convergir para ações de superação, reforçando e ampliando questões já apresentadas por André (2001) e Klüber (2017), ou seja,

valorizam a articulação entre teoria e prática na formação docente, reconhece a importância dos saberes da experiência e da reflexão crítica na melhoria da prática, atribuem ao professor um papel ativo no próprio processo de desenvolvimento profissional, e defendem a criação de espaços coletivos na escola para desenvolver comunidades reflexivas (ANDRÉ, 2001, p. 57).

A pesquisa de Forner (2018), além de ter Paulo Freire como principal referencial teórico, discutiu e problematizou questões relacionadas ao currículo das escolas e as possibilidades da Modelagem em sala de aula, refletiu sobre a cultura da performatividade (BALL, 2005), conceito cunhado para expressar os efeitos da globalização no meio educacional, existente nas escolas, e propôs alternativas para subverter o que está posto. Ao longo de toda investigação, os diálogos se deram em diversos temas e por diferentes perspectivas, principalmente aquelas que envolviam aspectos do legado de Freire, do currículo e apresentavam possibilidades do trabalho com a Modelagem a partir do que os professores vivenciaram, expressaram e desenvolveram, colaborativamente. As ideias discutidas em Forner (2018) têm sido ampliadas em trabalhos como Forner e Malheiros (2017, 2018a, 2018b, 2019a).

Além disso, essas discussões têm nos feito direcionar alguns olhares quanto ao papel dos alunos nas aulas de Matemática em que a Modelagem se faz presente. 


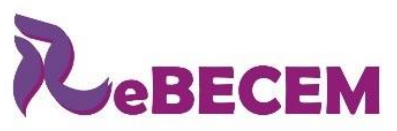

Revista Brasileira de Educação em

Ciências e Educação Matemática

DOI: http://dx.doi.org/10.33238/ReBECEM.2020.v.4.n.1.24566

Amparados em Freire, buscamos evidenciar os estudantes como sujeitos ${ }^{7}$ do processo de ensino e aprendizagem e assim, discutirmos suas percepções quanto as contribuições da Modelagem para ao ensino e aprendizagem de conteúdos matemáticos. Identificamos que não há investigações nessa direção quando se almeja o desenvolvimento de uma atividade, a partir de análise da literatura (BRAGA; MALHEIROS, 2019), e então estamos desenvolvendo uma pesquisa a esse respeito (BRAGA, 2019).

Esses caminhos que temos buscado convergem com as ideias de Ira Shor, em diálogo com Freire, ao afirmar que "o objetivo principal, para mim, é que a teoria consiga abranger o cotidiano" (FREIRE; SHOR; 2011, p. 16), ou seja, temos buscado levar a Modelagem para os espaços de formação de professores, com vistas a sua chegada às salas de aula de Matemática. Acreditamos que a Modelagem possui um terreno fértil para desenvolvimento e implementação, mesmo que em um contexto no qual o currículo é prescrito e há uma cobrança velada para utilização dos materiais didáticos, conforme mencionado anteriormente. "O currículo passivo baseado em aulas expositivas não é somente uma prática pedagógica pobre. É o modelo de ensino mais compatível com a promoção da autoridade dominante na sociedade e com a desativação da potencialidade criativa dos alunos" (FREIRE; SHOR; 2011, p. 28).

Para romper com a atual estrutura vigente, entendemos que é preciso que professores e futuros professores de Matemática, para além de conviver com práticas de Modelagem, seja em seu caminhar educacional ou ao longo de seu processo formativo, proponham atividades que estejam vinculadas ao contexto dos alunos e os tornem capazes de identificar o papel da Matemática na sociedade. É preciso deixar claro que a educação não é neutra e que é, sim, um ato político (FREIRE; SHOR, 2011). Ou seja, entendemos ser possível inserir a Modelagem em um contexto imerso na cultura da performatividade, por meio de diálogo e colaboração entre e com os professores, assim como a partir do conhecimento desses professores das possibilidades de relação entre a Modelagem e o que está posto nos materiais didáticos (FORNER, 2018; HONORATO, 2016).

Desse modo, compreendemos que precisamos partir daquilo que temos para termos a escola que queremos, uma escola baseada em uma perspectiva libertadora da educação (FREIRE, 2005). Para isso, é necessário que adotemos uma postura de pesquisadores, ou seja, olhemos para sala de aula e analisemos as relações que ali ocorrem

\footnotetext{
${ }^{7}$ Sujeito aqui concebido na perspectiva de Paulo Freire, ou seja, um homem enraizado historicamente e que expressa sua humanização.
} 
DOI: http://dx.doi.org/10.33238/ReBECEM.2020.v.4.n.1.24566

e assim possamos propor ações ou abordagens que melhorem o ensino e a aprendizagem da Matemática em nossas escolas.

Temos visto a Modelagem como uma possível forma de resistência ao modelo educacional que tem sido proposto, e muitas vezes imposto ${ }^{8}$, no qual, o que interessa é o desempenho dos estudantes nas avaliações em larga escala, e não a formação efetiva do sujeito. E, para resistir, é preciso buscar formas de superar a lista de conteúdos da BNCC (BIGODE, 2019), enquanto ela estiver em vigor. Ira Shor, em diálogo com Freire, afirma que "esses programas padronizados dão pouca autonomia para que professores e alunos reinventem o conhecimento existente" (FREIRE; SHOR, 2011, p. 129), então percebemos que um dos nossos trabalhos é buscar brechas para que seja possível que a Matemática ensinada em sala de aula faça sentido para os estudantes e possibilite que eles ampliem sua leitura de mundo, se conscientizem e se emancipem. E, para isso, trabalhar com professores e futuros professores de Matemática é fundamental.

Assim, advogamos em prol do movimento no qual as pesquisas, ao refletirem sobre o cotidiano da escola, traz contribuições para a formação dos futuros professores e nesse caminhar reflexivo propõe ações efetivas que exercem papel de impacto em direção a melhorias no ensino e na aprendizagem, mudando a triste realidade de algumas escolas e também no processo transformador e emancipador dos sujeitos.

\section{Considerações finais}

Tratamos neste artigo, de trazer para o debate, algumas considerações acerca da formação de professores em Modelagem e as relações com a escola pública, a partir da ideia de que a formação deva ser algo permanente e não pontual. Advogamos a favor da escola como, também, um lócus privilegiado de formação professores e de futuros professores, pois entendemos que nela é que diversas relações se evidenciam e que podem ser superadas.

Para isso, não negligenciamos algumas adversidades que tem acometido nossas instituições escolares, e entendemos que devemos fomentar ações formativas que sejam feitas "com" a escola e não "para" a escola. Assim, consideramos que a formação do professor pode ser em conjunto com a sala de aula, numa perspectiva freireana, dialógica, pois entendemos que "a educação autêntica, [...] não se faz de A para B ou de A sobre B,

\footnotetext{
${ }^{8}$ Em Forner e Malheiros (2019c) apresenta-se a Modelagem como uma possível resistência à cultura da performatividade e a opressão que se instala no contexto das escolas estaduais paulistas.
} 
DOI: http://dx.doi.org/10.33238/ReBECEM.2020.v.4.n.1.24566

mas de A com B, mediatizados pelo mundo" (FREIRE, 2005, p. 97, grifo do autor). Dessa forma, devemos escutar e dialogar com aqueles que estão diretamente envolvidos com os estudantes, no "chão da escola".

Diante dessas questões, entendemos que nossas pesquisas têm que estar cada vez mais intimamente relacionadas com a sala de aula e, para isso, propomos a Modelagem como uma das abordagens que permeie as práticas na universidade e não como algo isolado.

Frente ao contexto opressor que vislumbramos no sistema educacional brasileiro, entendemos a Modelagem como uma abordagem que pode ter convergência com ações de insubordinação criativa (D'AMBROSIO; LOPES, 2015), entendidas como ações que visam contrapor o que está posto e determinado. Somente sendo insubordinados seremos capazes de reverter esse quadro de fracasso que permeia o ensino de Matemática, fruto da cultura da performatividade que perpassa as escolas e, assim, caminharmos para ações que possam transformar a realidade de muitos de nossos estudantes, carentes de ações emancipatórias.

Ponderamos ser importante que professores e licenciandos fiquem atentos as possibilidades que os sistemas de ensino ofereça, mesmo com sua rigidez. Assim, percebemos ser necessário encontrar caminhos para subversão do sistema. Um deles pode ser a possibilidade de aliar a Modelagem com os materiais didáticos disponíveis na escola, cumprindo o currículo e para além, possibilitando a discussão do papel da Matemática na sociedade. Para nós, esse não é o melhor cenário, mas acreditamos que possa ser o início de uma mudança no contexto escolar.

Entendemos que a comunidade acadêmica e a dos professores da Educação Básica são diferentes em suas próprias práticas e saberes, no entanto "por mobilizarem saberes matemáticos e didático-pedagógicos que perpassam as práticas dessas duas comunidades, elas podem desenvolver conjuntamente ou dialogicamente" (FIORENTINI, 2013, p. 64).

Compreendemos, ainda, que a formação do professor deveria ocorrer para além da inicial e continuada, e sim, uma formação permanente com a estruturação de Espaços Colaborativos de Formação em Modelagem, com o intuito de que os professores participantes possam discutir e dialogar sobre essa tendência e ainda, elaborar colaborativamente atividades para serem desenvolvidas em suas salas de aulas, considerando o contexto em que estão inseridos. Dessa forma, poderão confrontar os seus saberes e os ressignificarem a partir de suas vivências e discussões com os demais participantes (FORNER, 2018) e incorporar em suas práticas pedagógicas docentes. 


\section{Referências}

DOI: http://dx.doi.org/10.33238/ReBECEM.2020.v.4.n.1.24566

ANDRÉ, M. Pesquisa, Formação e Prática Docente. In: ANDRÉ, M. (org.) O Papel da Pesquisa na Formação e na Prática dos Professores. 11. ed. Campinas: Papirus, 2001.

BALL, S. J. Profissionalismo, gerencialismo e performatividade. Cadernos de Pesquisa, v. 35. n. 126. p. 539-564. set/dez 2005.

BARBOSA, J. C. Modelagem Matemática: concepções e experiências de futuros professores. 2001. 253f. Tese (Doutorado em Educação Matemática) - Instituto de Geociências e Ciências Exatas, Universidade Estadual Paulista “Júlio de Mesquita Filho," Rio Claro, 2001.

BARBOSA, J. C. Integrando Modelagem Matemática nas Práticas Pedagógicas. Educação Matemática em Revista, São Paulo, ano 14, n. 26, Mar. 2009.

BARBOSA, J. C. Abordagens teóricas e metodológicas na Educação Matemática: aproximações e distanciamentos. In: OLIVEIRA, A. M. P.; ORTIGÃO, M. I. R. (orgs.) Abordagens teóricas e metodológicas nas pesquisas em educação matemática. Brasília: SBEM, 2018.

BIEMBENGUT, M. S. 30 Anos de Modelagem Matemática na Educação Brasileira: das propostas primeiras às propostas atuais. Alexandria: Revista de Educação em Ciência e Tecnologia, v.2, n.2, p.7-32, jul. 2009.

BIGODE. A. J. L. Base, que Base? O Caso da Matemática. In: CÁSSIO, F.; CATELLI JR., R. (org.) Educação é a Base? 23 Educadores Discutem a BNCC. São Paulo: Ação Educativa, 2019.

BRAGA, L. S. Modelagem e Educação Básica: um olhar para os alunos dos anos finais do ensino fundamental. In: ENCONTRO BRASILEIROS DE ESTUDANTES DE PÓSGRADUAÇÃO EM EDUCAÇÃO MATEMÁTICA, 23., 2019, São Paulo/SP. Anais... São Paulo, 2019.

BRAGA, L. S.; MALHEIROS, A. P. S. Pesquisas sobre Modelagem em Educação Matemática: que lugar ocupam os alunos? In: CONFERÊNCIA NACIONAL SOBRE MODELAGEM NA EDUCAÇÃO MATEMÁTICA, 11., 2019, Belo Horizonte. Anais... Belo Horizonte, 2019.

BRASIL. Conselho Nacional de Educação. Diretrizes Curriculares Nacionais para os Cursos de Matemática, Bacharelado e Licenciatura. CNE/CES 2001.

BRASIL. Secretaria de Educação Básica. Base Nacional Comum Curricular. Brasília, 2018. Disponível em http://basenacionalcomum.mec.gov.br/images/BNCC_EI_EF_110518_versaofinal_site.pdf. Acesso em: 04 dez. 2019

BRASIL. Secretaria de Educação Média e Tecnológica. Orientações Curriculares para o Ensino Médio, v. 2. Ciências da Natureza, Matemática e suas Tecnologias. Brasília: Ministério da Educação, 2006.

BRAZ, B. C. Aprendizagens sobre modelagem matemática em uma comunidade de prática de futuros professores de matemática. 2017. Tese (Doutorado em Educação para o Ensino de Ciências e Matemática) - Universidade Estadual de Maringá, Maringá, 2017. 


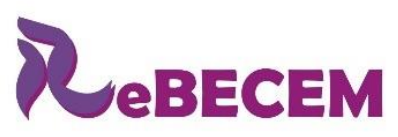

Revista Brasileira de Educação em

Ciências e Educação Matemática

ISSN 2594-9179

DOI: http://dx.doi.org/10.33238/ReBECEM.2020.v.4.n.1.24566

BRAZ, B. C. Contribuições da Modelagem Matemática na constituição de Comunidades de Prática Locais: Um estudo com alunos do Curso de Formação de Docentes. 2014.

Dissertação (Mestrado em Educação para o Ensino de Ciências e Matemática) - Universidade Estadual de Maringá, Maringá, 2014.

BURAK, D.; MALHEIROS, A. P. S. Modelagem em Educação Matemática: algumas pesquisas e práticas docentes na educação básica. In: BRANDT, C. F.; GUÉRIOS, E. (org.) Práticas e Pesquisas no Campo da Educação Matemática. Curitiba: CRV. 2017. p. 151-167.

CARA, D. Contra a barbárie, o direito à Educação. In: CÁSSIO, F. (org.) Educação contra a Barbárie: por escolas democráticas e pela liberdade de ensinar. São Paulo: Boitempo, 2019a.

CARA, D. O que Paulo Freire e Anísio Teixeira diriam sobre a BNCC? In: CÁSSIO, F.; CATELLI JR., R. (org.) Educação é a Base? 23 Educadores Discutem a BNCC. São Paulo: Ação Educativa, 2019b.

CARARO, E. F. F.; KLÜBER, T. E. Formação Continuada de Professores em Modelagem Matemática: um relato de experiência. Reflexão e Ação. Santa Cruz do Sul, v. 28, n. 1, p. 273289, jan./abr. 2020.

CÁSSIO, F. Existe vida fora da BNCC? In: CÁSSIO, F.; CATELLI JR., R. (org.) Educação é a Base? 23 Educadores Discutem a BNCC. São Paulo: Ação Educativa, 2019.

CEOLIM, A. J.; CALDEIRA, A. D. Obstáculos e Dificuldades Apresentados por Professores de Matemática Recém-Formados ao Utilizarem Modelagem Matemática em suas Aulas na Educação Básica. Bolema, Rio Claro, v. 31, p. 760-776, 2017.

CEOLIM, A. J.; Modelagem Matemática na Educação Básica: obstáculos e dificuldades apontadas por professores. 2015. Tese (Doutorado em Educação). Universidade Federal de São Carlos, São Carlos, 2015.

CRECCI, V. M.; FIORENTINI, D. Gestão do currículo de Matemática sob diferentes profissionalidades. Bolema, Rio Claro, v. 28, n. 49, p. 601-620, ago. 2014.

DEMO, P. Introdução à Metodologia da Ciência. 3. ed. São Paulo: Atlas, 1995.

D’AMBROSIO, B. S.; LOPES, C. E. Insubordinação Criativa: um convite à reinvenção do educador matemático. Bolema, Rio Claro, v. 29, n. 51, p. 1-17, abr. 2015.

FERNANDES, F. S. A quinta história: composições da educação matemática como área de pesquisa. 2014. Tese (Doutorado em Educação Matemática) - Instituto de Geociências e Ciências Exatas (IGCE), Universidade Estadual Paulista (UNESP), Rio Claro, SP, 2014.

FILLOS, L. M. Modelagem Matemática nos anos 1980: narrativas e itinerários de cursos de especialização. 2019. Tese (Doutorado em Educação Matemática) - Instituto de Geociências e Ciências Exatas (IGCE), Universidade Estadual Paulista (UNESP), Rio Claro, SP, 2019.

FIORENTINI, D. A Investigação em Educação Matemática desde a perspectiva acadêmica e profissional: desafios e possibilidades de aproximação. Cuadernos de Investigación y

Formación en Educación Matemática, Costa Rica, Año 8, n. 11, p. 61-82, 2013.

FORNER, R.; MALHEIROS, A. P. S. Situações-limites, Utopia, Inéditos-Viáveis e Insubordinação Criativa em práticas de Modelagem. In: CONFERÊNCIA NACIONAL SOBRE MODELAGEM NA EDUCAÇÃO MATEMÁTICA, X, 2017, Maringá, Anais... Maringá, 2017. 
DOI: http://dx.doi.org/10.33238/ReBECEM.2020.v.4.n.1.24566

FORNER, R. Modelagem Matemática e o Legado de Paulo Freire: relações que se estabelecem com o currículo. 2018. Tese (Doutorado em Educação Matemática). Universidade Estadual Paulista, Rio Claro, 2018.

FORNER, R.; MALHEIROS, A. P. S. Modelagem Matemática e Currículo: um caminho entre as situações-limites e os inéditos-viáveis. In: SEMINÁRIO INTERNACIONAL DE PESQUISA EM EDUCAÇÃO MATEMÁTICA, 7., 2018, Foz do Iguaçu. Anais... Foz do Iguaçu, 2018a.

FORNER, R.; MALHEIROS, A. P. S. Paulo Freire e Educação Matemática: em busca de uma forma matemática de ler o mundo - possibilidades e relações que podem se dar a partir da Modelagem. In: CONGRESSO INTERNACIONAL PAULO FREIRE: O LEGADO GLOBAL, 2., 2018, Belo Horizonte. Anais... Belo Horizonte, 2018b.

FORNER, R. MALHEIROS, A. P. S. Modelagem e o Legado de Paulo Freire: Sinergias e Possibilidades para a Educação Básica. Revista de Educação Matemática, São Paulo, v. 16, n. 21, p. 57-70, jan. /abr. 2019a.

FORNER, R. MALHEIROS, A. P. S. O que a Modelagem pode mudar com a escola? E o que a escola pode mudar com a Modelagem? In: XI CONFERÊNCIA NACIONAL SOBRE

MODELAGEM NA EDUCAÇÃO MATEMÁTICA, 11., 2019, Belo Horizonte. Anais... Belo Horizonte: UFMG, 2019b. v. 1. p. 1-11.

FORNER, R. MALHEIROS, A. P. S. Entre contextos opressivos e reguladores: a Modelagem como possível resistência à Cultura da Performatividade. Perspectivas da Educação

Matemática, INMA/UFMS, v. 12, n. 30, p. 538-558, 2019c.

FOSS, A. M.; KLÜBER, T. E. Sentidos que Sustentam Argumentos sobre os Obstáculos para a Inserção da Modelagem Matemática na Escola. In: CONFERÊNCIA NACIONAL SOBRE MODELAGEM NA EDUCAÇÃO MATEMÁTICA, 11., 2019, Belo Horizonte. Anais... Belo Horizonte: UFMG, 2019. v. 1. p. 1-15.

FREIRE, P. Pedagogia da Autonomia: saberes necessários à prática educativa. Rio de Janeiro: Paz e Terra, 2010.

FREIRE, P. Pedagogia do Oprimido. 49ª Reimpressão. Rio de Janeiro: Paz e Terra, 2005.

FREIRE, P. Pedagogia da Indignação: cartas pedagógicas e outros escritos. São Paulo: Editora UNESP, 2000.

FREIRE, P.; FAUNDEZ, A. Por uma Pedagogia da Pergunta. 7. ed. Rev. Ampliada. Rio de Janeiro: Paz e Terra, 2011.

HONORATO, A. H. Modelagem Matemática e o Material Didático do Estado de São Paulo: diálogos em um trabalho com licenciandos. 2016. Dissertação (Mestrado em Educação Matemática) - Instituto de Geociências e Ciências Exatas (IGCE), Universidade Estadual Paulista (UNESP), Rio Claro - SP, 2016

KLÜBER, T. E. Formação de Professores em Modelagem Matemática na Educação Matemática Brasileira: questões emergentes. Educere et Educare, Cascavel, v.12. n.24. jan./abr, 2017.

MAGNUS, M. C. M. Modelagem Matemática em sala de aula: principais obstáculos e dificuldades em sua implementação. Dissertação (Mestrado) - Programa de Pós- Graduação em 
DOI: http://dx.doi.org/10.33238/ReBECEM.2020.v.4.n.1.24566

Educação Científica e Tecnológica da Universidade Federal de Santa Catarina, Florianópolis, SC, 2012.

MALHEIROS, A. P. S. Modelagem em Aulas de Matemática: reflexos da formação inicial na Educação Básica. Perspectivas da Educação Matemática, v. 9, p. 1151-1167, 2016

MALHEIROS, A. P. S. Contribuições de Paulo Freire para uma compreensão da Modelagem na Formação Inicial de Professores de Matemática. Boletim do GEPEM. v. 64. 2014, p. 1-12.

MALHEIROS, A. P. S.; HONORATO, A. H. A. Modelagem nas Escolas Estaduais Paulistas: possibilidades e limitações na visão de futuros professores de Matemática. Educere At Educare, Cascavel, v. 12, jan./abr. 2017.

MIZUKAMI, M. G. N. Aprendizagem da docência: conhecimento específico, contextos e práticas pedagógicas. In: NACARATO, A. M.; PAIVA, M. A. V. (org.). A formação do professor que ensino matemática: perspectivas e pesquisas. Belo Horizonte: Autêntica, 2006. p. 213-231.

MUTTI, G. S. L.; KLÜBER, T. E. Aspectos que constituem práticas pedagógicas e a formação de professores em Modelagem Matemática. Alexandria, Florianópolis, v. 11, n. 2, nov. 2018.

PARANÁ. Secretaria de Estado da Educação. Diretrizes Curriculares da Educação Básica Matemática. Paraná: SEED, 2008.

PENTEADO, M. G. Novos Atores, Novos Cenários: Discutindo a Inserção dos Computadores na Profissão Docente. In: BICUDO, M. A. V. (ed.). Pesquisa em Educação Matemática: Concepções e Perspectivas. São Paulo, Editora UNESP, 1999. p. 297 - 313.

SÃO PAULO. Secretaria da Educação. Currículo do Estado de São Paulo:

Matemática e suas tecnologias / Secretaria da Educação; - 1. ed. atual. - São Paulo, 2012.

SÃO PAULO. Secretaria da Educação. Currículo Paulista. 1.ed. Atual. São Paulo: SE, 2019

SILVEIRA, E.; CALDEIRA, A. D. Modelagem na sala de aula: resistências e obstáculos. Bolema, Rio Claro, v. 26, n. 43, p. 1021-1047, ago. 2012.

TARDIF, M. Saberes docentes e formação profissional. 14. ed. Petrópolis: Vozes, 2012.

TROMBETA, S.; TROMBETTA, L. S. Inacabamento. In: STRECK, D. R.; REDIN, E.; ZITOSKI, J. J. (org.). Dicionário Paulo Freire. 3. ed. $1^{\text {a }}$ reimp. Belo Horizonte: Autêntica Editora, 2017. p. 221-222.

Convidado em: 06 de dezembro de 2019

Submetido em: 16 de abril de 2020

Revisado em: 27 de abril de 2020 